\title{
A child with purulent pericarditis and Streptococcus intermedius in the presence of a pericardial teratoma: An unusual presentation
}

\author{
Laura Presnell, ACNP, ${ }^{\mathrm{a}}$ Katsuhide Maeda, MD, ${ }^{\mathrm{a}}$ Michael Griffin, MD, ${ }^{\mathrm{b}}$ and David Axelrod, MD, ${ }^{\mathrm{a}}$ Palo Alto \\ and San Mateo, Calif
}

\begin{abstract}
A 23-month-old girl with no previous cardiac or medical history presented with 10 days of fever and malaise despite initiation of antibiotics on day 4 of fever. After a chest radiograph showed an enlarged cardiac silhouette, an echocardiogram was obtained that showed a large, circumferential, organized, cystic-appearing pericardial effusion. There was exaggerated respirophasic variation across the mitral inflow and aortic outflow ( $>35 \%$ ) consistent with echocardiographic evidence of pericardial tamponade.
\end{abstract}

Because of concern for the possibility of impending cardiac tamponade, the patient was admitted to the pediatric cardiovascular intensive care unit. There were no clinical signs of cardiac tamponade on admission. Laboratory evaluation revealed a white blood cell count of $22,500 / \mu \mathrm{L}$ and a C-reactive protein level of $15.1 \mathrm{mg} / \mathrm{dL}$. The effusion was not amenable to percutaneous drainage because of its location and loculated appearance; therefore, she was taken to the operating room for surgical drainage of the effusion.

The surgeon performed a full sternotomy and noted a thickened pericardium. On initial opening of the pericardium, turbid fluid was expressed. The entire pericardial space was then visualized and purulent discharge was exposed and evacuated. There were multiple pockets of pus around the heart, including a large area adjacent to the aorta and on the pulmonary artery that appeared to be an organized mass. Because of concern for the potential future development of constrictive pericarditis, the scar tissue around the heart was resected and an anterior pericardiectomy was performed. Pathologic evaluation of the mass demonstrated a pericardial teratoma with mature welldifferentiated cells and clear tumor margins. Intraoperative cultures grew Streptococcus intermedius, which was susceptible to ceftriaxone. All blood and urine cultures remained negative. The patient's postoperative course was uncomplicated. She was extubated on postoperative day 2 and her

\footnotetext{
From the Pediatric Cardiac Intensive Care Unit, ${ }^{a}$ Lucile Packard Children's Hospital at Stanford, Palo Alto, Calif; and Children's Cardiology of the Bay Area, ${ }^{\text {b }}$ San Mateo, Calif

Disclosures: David Axelrod reports consulting fees from Astellas Pharma. All other authors have nothing to disclose with regard to commercial support.

Received for publication Oct 23, 2013; accepted for publication Nov 11, 2013; available ahead of print Dec 27, 2013.

Address for reprints: Laura Presnell, ACNP, Pediatric Cardiac Intensive Care Unit, Lucile Packard Children's Hospital at Stanford, 725 Welch Rd, Palo Alto, CA 94304 (E-mail: lpresnell@gmail.com).

J Thorac Cardiovasc Surg 2014;147:e23-4

$0022-5223 / \$ 36.00$

Copyright (C) 2014 by The American Association for Thoracic Surgery

http://dx.doi.org/10.1016/j.jtcvs.2013.11.025
}

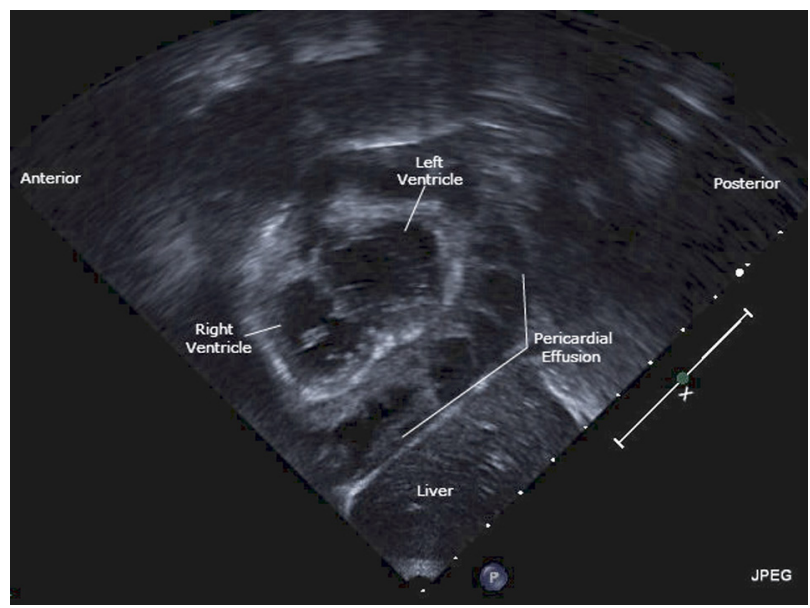

FIGURE 1. Subxyphoid short-axis image showing a large loculated pericardial effusion.

infectious markers normalized. She was discharged on postoperative day 8 with a peripherally inserted catheter and a 3-week course of intravenous ceftriaxone. Outpatient follow-up with the pediatric oncologist revealed that the tumor markers $\alpha$-fetoprotein and human chorionic gonadotropin were normal after resection. A computed tomography scan of her chest 1 week after hospital discharge showed no intrapericardial mass or fluid and no evidence of metastasis.

\section{DISCUSSION}

Pericardial teratomas are rare mediastinal tumors. ${ }^{1}$ Most present in infancy or childhood with symptoms of

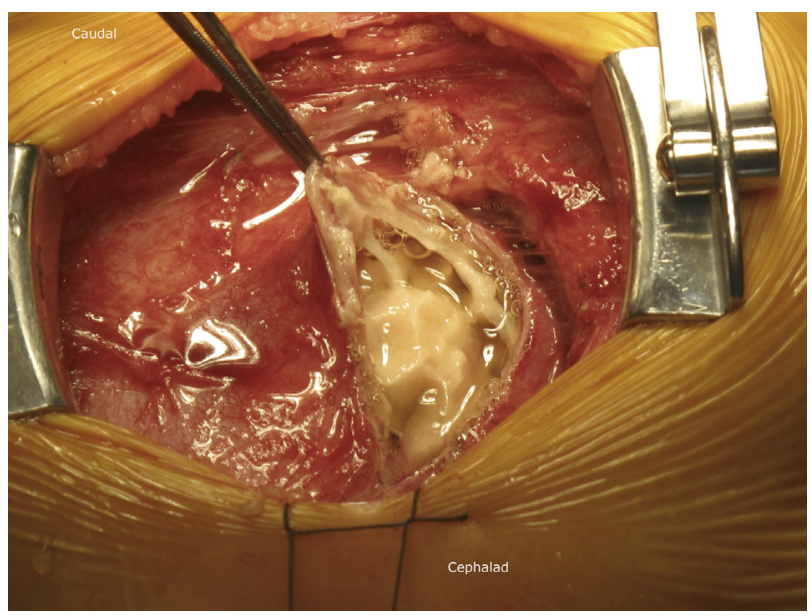

FIGURE 2. After removal of the anterior pericardium, the entire heart and great vessels are covered in purulent deposits. 
respiratory distress or cardiac tamponade. ${ }^{1,2}$ Purulent pericarditis is an infection within the pericardial space. ${ }^{3}$ With the development of broad-spectrum antibiotics, the incidence of purulent pericarditis has decreased dramatically and has become rare in healthy infants and children. ${ }^{4}$ Of the small number of documented cases of purulent pericarditis in children in the literature, the most common organisms found are Staphylococcus aureus, Streptococcus pneumoniae, and Haemophilus influenzae. ${ }^{3}$ Streptococcus intermedius is not a common cause of pericarditis. ${ }^{3,4}$

The case presented is unique in several ways. First, purulent pericarditis in an otherwise healthy child is rare. Streptococcus intermedius is often not present with purulent pericarditis in adults and has not been previously reported as a pathogen in children with purulent pericarditis. In addition, children with a pericardial teratoma most often present with respiratory distress or clinical symptoms of cardiac tamponade. In contrast, our patient presented primarily with concern for an infectious process. This was not only an unusual case of purulent pericarditis in an otherwise healthy child; it was an unusual presentation of a pericardial teratoma as she had no evidence of clinical cardiac tamponade or respiratory distress. This is the first reported case of purulent pericarditis in the presence of a pericardial teratoma in a child. It is also the first reported case of purulent pericarditis with Streptococcus intermedius in a child.

\section{References}

1. Becker AE. Primary heart tumors in the pediatric age group: a review of salient pathologic relevant for clinicians. Pediatr Cardiol. 2000;21:317-23.

2. Gunther T, Schreiber C, Noebauer C, Eicken A, Lange R. Treatment strategies for pediatric patients with primary cardiac and pericardial tumors: a 30-year review. Pediatr Cardiol. 2008;29:1071-6.

3. Parikh SV, Memon N, Echols M, Shah J, McGuire DK, Keeley EC. Purulent pericarditis report of 2 cases and review of literature. Medicine. 2009; 88:52-65.

4. Tokuyasu H, Saitoh Y, Harada T, Touge H, Kawasaki Y, Maeda R, et al. Purulent pericarditis caused by the Streptococcus milleri group: a case report and review of the literature. Intern Med. 2009;48:1073-8.

\section{Awake uniportal video-assisted thoracoscopic metastasectomy after a nasopharyngeal carcinoma}

Carlos Galvez, MD, Sergio Bolufer, MD, Jose Navarro-Martinez, MD, DEAA, and Francisco Lirio, MD, Alicante, Spain

Video clip is available online.

A 70-year-old man with a previous nasopharyngeal carcinoma treated with chemoradiotherapy in 2011, was found to have 2 nodules in the left upper lobe at follow-up (Figure 1, A). A fine-needle aspiration biopsy of the bigger lesion led to a diagnosis of metastatic disease. We suggested an awake procedure and the patient signed written informed consent.

\section{SURGICAL TECHNIQUE}

A thoracic epidural catheter was inserted at the T4-T5 level with a single injection of $15 \mathrm{~mL}$ of bupivacaine $0.5 \%$ and left in place during the procedure, but removed

From the University General Hospital of Alicante, Alicante, Spain.

Disclosures: Authors have nothing to disclose with regard to commercial support.

Received for publication Sept 5, 2013; revisions received Oct 20, 2013; accepted for publication Oct 25, 2013; available ahead of print Dec 2, 2013.

Address for reprints: Carlos Galvez, MD, C/Pintor Baeza, 12. 03010, Alicante, Spain (E-mail: carlos.galvez.cto@gmail.com).

J Thorac Cardiovasc Surg 2014;147:e24-6

$0022-5223 / \$ 36.00$

Copyright (c) 2014 by The American Association for Thoracic Surgery

http://dx.doi.org/10.1016/j.jtcvs.2013.10.041 at the end of the operation. Pressure of carbon dioxide $\left(\mathrm{PaCO}_{2}\right)$ and oxygen $\left(\mathrm{PaO}_{2}\right)$ was measured during the surgery. Midazolam and fentanyl were administered intravenously to keep the patient calm, but under conscious sedation throughout the procedure. He was placed in right lateral decubitus position and continued breathing spontaneously (Figure 1, B). An emergency protocol had been developed.

A 5-cm single incision in the fifth intercostal space (uniportal video-assisted thoracoscopic surgery [VATS]) was performed resulting in a surgical pneumothorax with excellent lung collapse. Mild hypoxemia occurred with $88 \%$ oxygen saturation, but the patient remained asymptomatic (Figure 1,C). We liberated some adhesions with the ultrasonic scalpel (Sonicision, Covidien, Mansfield, Mass) and palpated both nodules manually in the upper lobe. A wedge resection was performed with EndoGIA thick loads (Autosuture, Norwalk, Conn) and the specimen was removed with a specimen bag (Figure 1,D). Analysis of frozen sections of the nodules showed $1 \mathrm{~cm}$ of macroscopic free margins. A 24-Fr chest drain was inserted through the single port and connected to suction under $10 \mathrm{~cm} \mathrm{H}_{2} \mathrm{O}$; the patient was asked to breathe deeply and cough to completely reexpand the lung. 